\title{
CRONICA DE LA SEMANA DE ESTUDIOS SOBRE LA CONSTITUCION Y LA ADMINISTRACION LOCAL
}

$342.4: 352$

por

Fernando López Ramón

1) Contribuyendo a las numerosas actividades culturales desarrolladas con motivo del cuarto centenario de la Universidad de Zaragoza, el Instituto de Estudios de Administración Local organizó, en la misma ciudad, la denominada «I Semana de Estudios sobre la Constitución y la Administración Local», durante los días 24 al 28 de octubre de 1983.

A lo largo de cinco sesiones vespertinas, un elenco de prestigiosos administrativistas ilustró a un público numeroso y heterogéneo con una serie de conferencias sobre la problemática jurídica de las Corporaciones locales. Debe destacarse el éxito de la "Semana» en lo referente a público asistente; el salón de plenos de la Diputación Provincial de Zaragoza, donde se impartían las conferencias, quedó pequeño, hasta el punto de hacer necesaria la instalación de aparatos de televisión en los amplios pasillos del edificio. Probablemente, la calidad de los conferenciantes, unida a la actualidad de las materias tratadas, determinaron el éxito organizativo.

2) Día 24. La primera conferencia corrió a cargo del profesor Luis Martín Rebollo, Catedrático de Derecho Administrativo en la Universidad de Extremadura, con el título La Administración local: una perspectiva de futuro. 
Empezó el conferenciante destacando la inserción de la problemática local en el cuadro, más amplio, de las coordenadas políticas e ideológicas de la distribución territorial del Poder, reflexionando sobre la relevancia de las cuestiones organizativas en la configuración de efectivas prestaciones públicas al ciudadano, es decir, su importancia para acercarnos a la forma del Estado social, de acuerdo con las pautas que, entre otros preceptos, muy destacadamente, contiene el artículo 9, 2. ${ }^{\circ}$, de la Constitución. En este sentido, resaltó la tradicional vertiente prestacional de las Administraciones locales, recordando algunas previsiones jurídico-positivas, como la obligatoriedad de los servicios mínimos en la Ley de Régimen local, los estándares para la planificación urbanística en la Ley del Suelo... Idea que debe ser completada con el elemento participativo; lo característico del Régimen local sería, pues, no sólo el prestar unos servicios, sino el hacerlo en régimen de autogobierno.

Un régimen de autogobierno que, por supuesto, no pierda de vista la unidad global del Estado ni la perspectiva regional. Refirió así el conferenciante diversas experiencias de articulaciones indebidas entre las Administraciones locales y las Administraciones gestoras de intereses públicos más amplios, tanto por excesos centralistas como por razones de signo contrario. Claramente habló de lo endeble de un supuesto principio de autosuficiencia local, como prueba la simple mención de algunas materias necesitadas de enfoques más amplios: el urbanismo, la sanidad, el consumo, la seguridad...

En su opinión, la respuesta histórica a la exacerbación del Régimen local vino dada, en nuestra patria, por el surgimiento de poderosas ramas periféricas de la Administración del Estado y por el vaciado de las Haciendas locales. Elementos que han perdurado, que se han desarrollado en el tiempo, determinando una profunda crisis del municipalismo, a pesar de los cambios sociales operados.

En esa situación empobrecida de la Administración local, se ubica la profunda inflexión que, en toda la vida pública, significa la Constitución de 1978. Ciertamente, el texto fundamental sólo ofrece unas cuantas pautas claras, unas previsiones que pueden reducirse a una serie de puntos muy concretos, pero que, no obstante, dado su contraste con la situación anterior y su incidencia en la reforma del Régimen local, el conferenciante se ocupó en destacar: los Municipios son unos Entes sobre cuya base se organiza territorialmente el Estado, dotados de autonomía administrativa; su existencia está constitucionalmente garantizada, pero los contenidos sobre 
los que opera la autonomía local quedan remitidos al legislador ordinario, debiendo, eso sí, arbitrarse unas Haciendas locales congruentes con el haz de funciones y competencias determinado por la ley; los aspectos básicos del Régimen local se reservan al Estado, de forma que en las Administraciones locales pueden incidir normas estatales y autonómicas; en concreto, la atribución de competencias locales se hará por el Estado o por las Comunidades Autónomas, en función de sus propias potestades legislativas.

A partir de estas coordenadas, el conferenciante esbozó una serie de ideas que podían servir para la reforma del Régimen local. Una reforma caracterizada por el intento de hacer realidad el principio de descentralización en todos los engranajes del Estado; una reforma que impregnada del significado democrático, participativo y de integración social que debe darse al Municipio, olvide todo intento de suprimir Municipios; una reforma que, al propio tiempo, asegure la necesaria eficacia técnica y económica de las Administraciones locales.

La reforma, pues, debería partir de la previsión de una pluralidad de soluciones para la heterogénea situación de los Municipios, profundizando, en todo caso, en el esencial punto de la consolidación de las Haciendas locales y en la problemática del personal, cuya movilidad, a juicio del orador, debería preverse. En cuanto a las competencias locales, afirmó, siguiendo recientes elaboraciones doctrinales, que la delimitación de áreas de la exclusiva competencia municipal conducía, en la práctica, a la afirmación del centralismo - de nivel estatal o regional一, siendo más adecuado arbitrar una participación competencial de las diversas Administraciones públicas sobre las mismas materias, con el recurso a fórmulas de coordinación, colaboración, cooperación. En esta línea, destacó la mala experiencia provocada por la ausencia de controles administrativos sobre las Corporaciones locales en la Ley 40/1981, de 28 de octubre, realzando la importancia - hoy en entredicho- de los cuerpos nacionales de Secretarios e Interventores locales.

3) El profesor Santiago MuÑoz MACHADO, Catedrático de Derecho Administrativo en la Universidad de Alcalá de Henares, disertó sobre Las relaciones entre las Administraciones del Estado y de las Comunidades Autónomas y las Corporaciones locales, realizando una exposición muy trabada en la que trató de tres grandes cuestiones: la distribución de competencias entre el Estado y las Comunidades Autónomas sobre la materia de Administración local, 
la posición constitucional de los Entes locales y el sistema de relaciones de estos Entes con el Estado y con las Comunidades Autónomas.

Comenzó destacando cómo el Régimen local se había construido en la Europa continental en torno a la idea, de origen francés, de que era necesario reconocer una esfera de poder municipal, un conjunto de competencias ejercido separadamente por los Municipios; idea plasmada en la regulación exhaustiva de la organización y las competencias municipales en una Ley de Régimen local.

Desde el punto de vista de la distribución de competencias entre el Estado y las Comunidades Autónomas, esa concepción llevaría aparejada la consideración del Régimen local como una materia, conduciendo a la configuración de la autonomía local como un conjunto de poderes tasados y prefijados.

Tal posición ha sido sometida a revisión doctrinal en Alemania, donde el Régimen local está atribuido a la competencia de los Estados miembros. Conforme a esos avances, el Régimen local no es ya una materia, sino una cuestión de autoorganización del Estado miembro, que no comprende, pues, el elenco concreto de competencias de las Administraciones locales. La atribución de competencias locales está en función de la competencia legislativa sobre las distintas materias; de esta manera, el contenido de la autonomía local no consiste ya en una atribución única y permanente de poderes, sino en el reconocimiento general de una esfera de intereses locales en relación con las distintas materias prefijadas por el legislador del Régimen local, esfera cuyo nivel competencial sería concretado por el legislador sectorial (sea la Federación o sean los Estados miembros).

En España, no parece posible considerar a los Entes locales como parte de la estructura organizativa de las Comunidades Autónomas, habida cuenta que, según el artículo 137 de la Constitución, es el Estado quien «se organiza territorialmente en Municipios, en Provincias y en las Comunidades Autónomas que se constituyan". Aunque también debe tenerse en cuenta la general aceptación de competencias de las Comunidades en relación con los Entes locales, ex artículo $148,1^{\circ}, 2^{2}{ }^{a}$, de la Constitución, y la consideración de las Administraciones locales como una pieza de las Comunidades locales en sus Estatutos.

El problema reside en determinar si el Estado puede relacionarse con los Entes locales, lo que actualmente parece factible, a la vista de la declaración de la sentencia del Tribunal Constitucional 
de 23 de diciembre de 1982 sobre el carácter bifronte del Régimen local, esto es, sobre la consideración de las Administraciones locales como piezas estructurales del Estado y de las Comunidades Autónomas. Para el conferenciante, las anteriores consideraciones debian conducir a que la futura ley estatal sobre el Régimen local recogiera una lista de materias competencia de los Entes locales, sin perjuicio de que la legislación sectorial precisara el alcance de esa competencia.

En cuanto a las relaciones del Estado y las Comunidades Autónomas con las Administraciones locales, se refirió a la idea según la cual el robustecimiento del poder local era conforme al principio democrático, tendiendo a configurarlo como un poder exento. Dejó reflejada la superación de esa idea por el entendimiento democrático de la propia Administración del Estado, que había llevado a concebir a las Administraciones locales como piezas del aparato estatal, aunque sin deducir de ello una subordinación jerárquica. Las técnicas de control de la Administración del Estado sobre las Corporaciones locales se establecen, en tal caso, distinguiendo entre los poderes propios de estas últimas y los que ejercen por delegación. Distinción difícil de aplicar en España, dada la inexistencia de un criterio de deslinde entre las competencias propias y delegadas de los Entes locales; si se importara, cabría el riesgo de que el legislador considerara delegadas todas las competencias locales, con la consiguiente intensificación de controles.

Las técnicas de relación entre Estado y Comunidades Autónomas con los Entes locales, en nuestro ordenamiento, consisten en la delegación de competencias y la gestión ordinaria de competencias autonómicas por las Diputaciones provinciales. Señaló que en el anteproyecto de Ley de Bases del Régimen local se permitía la delegación directa de competencias del Estado en las Administraciones locales, y asimismo, que la delegación en tales Administraciones por parte de las Comunidades Autónomas es meramente facultativa. También destacó que en todos los casos de delegación el Ente delegante no perdía las facultades de dirección.

En cuanto a la fórmula -importada parcialmente de Italia- de la gestión ordinaria de los servicios de las Comunidades Autónomas por las Diputaciones provinciales, puso de relieve que en ellas las Diputaciones quedaban convertidas en órganos de las Comunidades, con una actuación sometida a estricta subordinación jerárquica. En opinión del conferenciante, es dudoso el futuro de tal fórmula, 
aunque afirmó que de su éxito dependía la salud global del sistema de distribución territorial del poder; es decir, al no ser disponible — «desgraciadamente» valoró- la Provincia por la Comunidad Autónoma, sólo su utilización conforme a esta técnica podía evitar una densificación administrativa no deseable.

Terminó su exposición haciendo hincapié en la necesidad de un control administrativo sobre las Corporaciones locales. Discrepó de la doctrina que, sentada en la sentencia del Tribunal Constitucional de 2 de febrero de 1981 y desarrollada en la Ley 40/1981, lleva a considerar posibles únicamente tutelas de legalidad sobre los Entes locales; dijo que tal cosa sólo era admisible en el ámbito de los poderes propios. Concretamente, calificó la absoluta judicialización de los controles como un "puro disparate organizativo", afirmando que ningún sistema administrativo podía funcionar así, puesto que impedía el establecimiento de una relación de continuidad entre las distintas Administraciones.

4) Día 25. El profesor Juan Alfonso Santamaría Pastor, Catedrático de Derecho Administrativo en situación de supernumerario y Letrado de las Cortes Generales, dictó la única conferencia del día, titulada Regímenes locales especiales: el caso de los territorios históricos del País Vasco.

Comenzó indicando que el tema elegido, aparentemente, resultaba muy localizado; sin embargo, servía muy bien para aclarar la nebulosa que envuelve a todo lo foral, así como para perfilar los caracteres de un régimen provincial dotado, a su juicio, de gran singularidad y profunda carga de ejemplaridad.

El conferenciante recordó la perplejidad que le había suscitado la lectura de dos normas de la Constitución, en concreto, la disposición adicional $1 .^{\mathrm{a}}$, referida a los "derechos históricos de los territorios forales", y la disposición derogatoria, punto $2 .^{\circ}$, a propósito de la expresada derogación, «en cuanto pudiera conservar alguna vigencia», del Real Decreto de 25 de octubre de 1839 y de la Ley de 21 de julio de 1876 .

Los territorios forales mencionados en la citada disposición adicional no se identifican con algunas Comunidades Autónomas; aluden a las Provincias de Vizcaya, Guipúzcoa, Alava y Navarra, separadamente, imponiendo la adaptación de sus derechos históricos a las necesidades actuales, por los propios territorios y no por el Estado ni por las Comunidades Autónomas, aunque, eso sí, «en el marco de la Constitución y de los Estatutos de Autonomía». 
Tal interpretación viene confirmada por el Estatuto Vasco. El artículo 3 indica que la actualización de los derechos históricos corresponde a los territorios; competencia que, significativamente, aparece repetida en el artículo $24,2 .^{\circ}$, tras reseñar en el párrafo $1 .^{\circ}$ los poderes del País Vasco. En el artículo 25, al hablar del Parlamento Vasco, se tiene el cuidado de dejar a salvo las competencias de los territorios históricos, a los que se dedica el artículo 37. En definitiva, para el Estatuto Vasco los territorios históricos no son sólo unas Provincias, sino una pieza institucional básica de su autonomía. Afirmó el conferenciante que la autonomía vasca tenía dos fuentes: el Título VIII de la Constitución y los derechos históricos, que constituían el núcleo primario de tal autonomía.

Aseguró que la situación podía recibir una adecuada explicación histórica si se tenía en cuenta que el planteamiento de la autonomía vasca obedecía a dos líneas diferenciadas. La primera, la más antigua, supone la reivindicación frente al Estado de un status abolido en 1839 y 1876; es la exigencia de la reintegración foral, de corte provincialista. La línea autonomista global, simbolizada en la figura de Sabino Arana, es posterior en el tiempo. Con diversos datos, trató de demostrar el predominio histórico de la primera tendencia. Relató cómo en 1917 las Diputaciones Forales pidieron la reintegración foral de cada una de las Provincias; petición a la que parecía responder un proyecto de ley sobre autonomía provincial que en 1919 suscribía RoMANONES, sin prever ningún órgano de coordinación superior a las Provincias vascas. En 1924, la Sociedad de Estudios Vascos propugnaba asimismo una autonomía provincial, aunque incluyendo la organización interprovincial de algunos servicios. Entre otras referencias, destacó la estructura decididamente confederal con que el proyecto de Estella de 1932 diseñaba el Estado autónomo vasco, y si bien en las Cortes se borraron los datos confederales - con disgusto de los nacionalistas vascos-, en el Estatuto de 1936 persistía la relevancia dada a las Provincias.

Pasando ya a momentos más recientes, el conferenciante puso de relieve que el compromiso autonómico firmado por las fuerzas democráticas vascas en 1977 preveía la defensa del sustrato provincial; compromiso que dio fundamento al Real Decreto-ley de la preautonomía vasca, aunque, ciertamente, no sin modificaciones, puesto que en la propuesta de los parlamentarios vascos el régimen preautonómico era una adaptación del Estatuto de Estella, lo que no prevaleció en el resultado final. En cuanto al Estatuto de Auto. 
nomía vigente, destacó que en el texto definitivo había resultado menos centralista, en lo referido a la estructura interna de la Comunidad, que el proyecto de Guernica.

A la vista de estos antecedentes, la disposición adicional $1 .^{\mathrm{a}} \mathrm{de}$ la Constitución cobra un significado de gran relevancia. No es una norma complementaria del Estatuto, como de su lectura aislada hubiera podido pensarse, sino un paso previo: es decir, lo primero que hace la Constitución es admitir la tradicional reivindicación histórica, la reintegración foral. El proceso estatutario y autonomista no consiste sólo en crear una Comunidad Autónoma, sino, previamente, en arbitrar los mecanismos de actualización de unos derechos históricos.

Derechos históricos que ni la Constitución, ni el Estado, ni las instituciones vascas pueden menoscabar, aunque su actualización debe llevarse a cabo con observancia de la Constitución y dentro de la Comunidad Autónoma. Es decir, por una parte, esos derechos históricos no pueden afectar a las competencias del Estado, ex artículo $149,1 .^{\circ}$, de la Constitución, y, además, su reconocimiento no implica una desvalorización de la Comunidad Autónoma, dada la exigencia de que los asuntos de interés interprovincial pasen a depender de la misma Comunidad.

Los derechos históricos, precisó el conferenciante, configuran una forma diferenciada de gobierno local. Incluyen la potestad tributaria derivada del concierto y una serie de normas de competencia, organización y relativas a las relaciones interadministrativas de los Entes locales. No es posible catalogarlos con arreglo a un criterio histórico, dado que están en permanente formación, razón que aconseja acudir al estado actual de su evolución para determinar su alcance.

La materia de organización no plantea mayores problemas, al haber ejercido recientemente los propios territorios sus potestades en tal sentido. Más difícil solución presenta, sin embargo, la cuestión de las competencias de los territorios, sobre todo las referidas a Gujpúzcoa y Vizcaya. Históricamente, puede observarse que hasta 1876, las Provincias atendían los servicios que no podían llevar a cabo los Municipios aislados. A partir de esa fecha, con la ley abolitoria de los fueros, las Diputaciones asumieron mayores competencias, debido al exceso de recursos financieros derivado de los conciertos. En 1936, la pérdida del régimen foral para Vizcaya y Guipúzcoa supuso el anquilosamiento de sus competencias, desde el punto de vista 
histórico. Por el contrario, Alava conservó su poder económico, lo que condujo a un incremento de las competencias, reflejado en diversas normas estatales (Ley de Transportes Mecánicos por Carretera, Ley de Autopistas, reforma de la Ley del Suelo de 1975...).

Pues bien, habida cuenta de esta evolución, el conferenciante llegó a la conclusión de que las competencias provinciales derivadas de los derechos históricos, en la actualidad son las que ejerce Alava, único territorio en el que la evolución de las mismas no se paralizó, siempre y cuando tales competencias no correspondan ni al Estado ni a la Comunidad Autónoma por su Estatuto.

En cuanto a las relaciones de las Comunidades Autónomas con los territorios históricos, hizo hincapié en los problemas derivados de la atribución de la potestad recaudatoria a las Diputaciones Forales, que aportan un cupo a la Comunidad Autónoma. Se refirió también a la tendencia del Gobierno Vasco a menoscabar los derechos históricos, aunque éstos se encuentran defendidos por una Comisión Arbitral, prevista por el artículo 39 del Estatuto Vasco, en la que la Comunidad Autónoma y Diputaciones Forales están en pie de igualdad y cuyas decisiones se superponen al propio Parlamento Vasco.

En las relaciones de los territorios con los Municipios, destacó la tradicional existencia en las Diputaciones Forales de poderes de supremacía cuasijerárquica. El origen de tales poderes está en un curioso episodio ocurrido en 1853 , cuando las fuerzas vascas consiguen que el Ministro del Interior traspase las funciones de control sobre los Municipios de los Gobernadores civiles a las Diputaciones Forales. Ese traspaso de competencia -con unos contenidos de control más amplios de los tradicionales- se mantuvo en normas sucesivas, tal y como existía en 1853. Situación que no es homologable bajo la Constitución de 1978, por un principio de igualdad entre los Municipios; esto es, dado el reconocimiento constitucional de la autonomía municipal, sólo son admisibles controles de legalidad puntuales sobre la actividad de los Municipios. No hay, en cambio, inconveniente en que persistan los controles económicofinancieros.

Terminó el conferenciante haciendo una reflexión general, a la luz de la experiencia y la problemática vasca, sobre la tendencia innata a la centralización interna que acompaña el surgimiento de nuevas Entidades políticas; reflexión que puede ayudar a una mejor comprensión de las complejas relaciones entre Comunidades Autó- 
nomas y Diputaciones Provinciales. Asimismo, se preguntó si acaso el sentimiento de autonomía más acentuado no será en muchos lugares el provincial.

5) Día 26. El profesor Francisco Sosa WAGNER, Catedrático de Derecho Administrativo en la Universidad de León, en situación de excedencia especial por su cargo de Secretario General Técnico del Ministerio de Administración Territorial, habló de La Ley Básica de Régimen local.

Comenzó poniendo de relieve la posición, enormemente erosionada, que ocupaban las Corporaciones locales al inicio de la transición política, extendiéndose en datos sobre la invasión competencial del Estado a través de su actividad normativa; el rígido sistema de tutela que sufrían las Administraciones locales; la designación no democrática de sus autoridades; la debilidad de las Haciendas locales; la posición de inferioridad de las Corporaciones locales frente a los reglamentos estatales, debida a las trabas legitimadoras para el recurso contencioso-administrativo; el deterioro de las Diputaciones Provinciales.

Esos mecanismos van desmontándose. La Ley $40 / 1981$ ha acabado con los controles de oportunidad sobre la actividad local, de acuerdo con la tendencia y las pautas interpretativas fijadas por el Tribunal Constitucional en sus sentencias de 2 de febrero, 29 de abril y 28 de julio de 1981. La Ley de Elecciones locales impone un sistema democrático en la formación de los órganos colegiados de las Corporaciones locales. Las Haciendas locales han sido reforzadas (impuesto de radicación, licencia fiscal del impuesto industrial, aumento de los porcentajes de participación en los impuestos estatales...). Los inconvenientes legitimadores para la impugnación por las Corporaciones locales de los reglamentos estatales no han sido, sin embargo, totalmente superados, como prueba una jurisprudencia contradictoria que el conferenciante examinó (sentencias del Tribunal Supremo de 11 de abril y 20 de octubre de 1981, de 5 de enero y 5 de mayo de 1982), criticando duramente tal situación, incompatible, a su juicio, con el derecho a la tutela judicial efectiva que consagra el artículo 24 de la Constitución.

A pesar de los cambios operados, el conferenciante se mostró partidario de iniciar una reforma normativa del Régimen local, cuyo primer objetivo, a partir de la Constitución (en concreto, de su art. $\left.149,1^{\circ}, 18 .^{a}\right)$, consistiría en la aprobación por el Estado de una Ley Básica de Régimen local. Esa Ley debe regular las bases 
organizativas, de funcionamiento y régimen jurídico; bases desarrolladas por las Comunidades Autónomas y, en último extremo, por las ordenanzas locales. En cambio, el concreto haz de competencias locales vendría definido por la legislación sectorial -del Estado o de las Comunidades Autónomas, en función de la distribución de competencias-, que habría de respetar siempre el principio de dar un ámbito de actuación para los intereses locales.

Precisando más el posible contenido de la Ley Básica de Régimen local, el conferenciante se refirió al anteproyecto elaborado recientemente, todavía sin adecuada difusión, a la espera de una previa concertación política. En ese anteproyecto, la organización del Régimen local se basa en el reforzamiento de la figura del Alcalde, propiciando una fórmula presidencialista en la gestión municipal; las especialidades municipales -Comarcas, Areas metropolitanas...quedan remitidas a las Comunidades Autónomas; la Provincia se configura como garantía financiera de los servicios mínimos municipales, respetando los planes provinciales de obras y servicios. Se insiste en la judicialización del control de la actividad local, al margen de los instrumentos fiscalizadores que puedan diseñar las Comunidades Autónomas. El anteproyecto refuerza también las vías de participación ciudadana en la gestión local, regulando sistemas de información de los ciudadanos sobre tal gestión. Por último, en cuanto a la función pública, se establece el principio de autonomía de las Corporaciones locales en la selección de su personal; principio que no se traduce en la desaparición de los cuerpos nacionales, a través del arbitrio de una solución bifásica: reclutamiento nacional y facultades locales de selección entre los miembros del cuerpo. Incluso de cara a los funcionarios propios, el principio autonomista resulta compatible con la reserva al Estado de las bases generales de acceso y la configuración de los programas mínimos.

Por último, se refirió el conferenciante al desarrollo de la Ley básica por las Comunidades Autónomas. Habida cuenta de que sólo las Comunidades de primer grado son competentes para tal desarrollo, habrá que esperar al transcurso de los cinco años que posibilite la reforma de los Estatutos de las demás Comunidades, o bien, para esas Comunidades de segundo grado, utilizar la vía del artículo $150,2 .^{\circ}$, de la Constitución.

6) Cerró la sesión del día 26 el profesor Lorenzo MarTín-RetorTrLlo, Catedrático de Derecho Administrativo en la Universidad de 
Zaragoza, disertando sobre Las Corporaciones locales y el recurso constitucional de amparo.

La primera parte de su exposición estuvo dedicada a examinar la problemática del recurso de amparo contra actos de las Corporaciones locales. Se preguntaba el conferenciante si tiene sentido distraer la atención del Tribunal Constitucional para examinar un amparo contra Ente local. En su opinión, la legislación preconstitucional no dejaba prácticamente resquicios en el control jurisdiccional de las Administraciones locales, por lo que parecía de todo punto innecesario extender a las mismas el recurso de amparo. Ahora bien, dado que la Constitución generaliza el amparo en su artículo 53, 2. es lógico que la Ley Orgánica del Tribunal Constitucional haya tratado igual el amparo contra Corporaciones locales que los demás supuestos posibles.

Existe, no obstante, una cierta diferencia -al menos, sintáctica- en el tratamiento que el amparo contra actos de las Corporaciones locales recibe. El artículo 41 de la citada Ley Orgánica no menciona expresamente a las citadas Corporaciones al enumerar los Entes cuya actividad puede conducir a un recurso de amparo, si bien puedan quedar incluidas, sin mayores problemas, en la referencia a los «demás Entes públicos de carácter territorial». Sin embargo, sorprendentemente, el posterior artículo 43, al imponer en determinados casos el agotamiento de la vía judicial previa al amparo, no menciona, ni tan siquiera genéricamente, a las Administraciones locales. Para el conferenciante, de acuerdo con otros autores, parece claro que, pese a la omisión, es preciso agotar la vía judicial para acudir en amparo contra Corporaciones locales; la omisión, en realidad, no es sino un error material, puesto que las Cortes aprobaron un texto del artículo 43 de la Ley Orgánica del Tribunal Constitucional que incluía - al igual que el artículo 41- la mención a los «demás Entes públicos» en la exigencia de agotar la vía judicial.

Tras lo anterior, el conferenciante analizó la experiencia de los recursos de amparo contra Corporaciones locales, siguiendo las diversas resoluciones del Tribunal Constitucional: sobre pensiones de la MUNPAL - tema conexo- (sentencias de 11 de junio de 1981 y 4 de mayo de 1983); sobre separación del servicio de un funcionario (auto de 24 de septiembre de 1980); sobre sanciones urbanísticas (auto de 25 de mayo de 1983); sobre bienes municipales (sentencia de 20 de octubre de 1982)... Especial atención dedicó a la serie de 
sentencias dictadas sobre la posición de los Concejales y Alcaldes, en relación con el artículo $11,7^{\circ}$, de la Ley de Elecciones locales.

El conferenciante dedicó la última parte de su exposición a estudiar si las Corporaciones locales pueden ser titulares de derechos fundamentales $y$, en consecuencia, si pueden solicitar amparo ante el Tribunal Constitucional. En este sentido, recordó el contenido de la sentencia de 14 de marzo de 1983, que admite una demanda de amparo de la Diputación Foral de Navarra en cuanto Ente local, por supuesta violación del artículo 24 de la Constitución.

7) Día 27. Inició la sesión el profesor Ramón PaRAda Vázquez, Catedrático de Derecho Administrativo en la Universidad Nacional de Educación a Distancia hablando de Descentralización política y Administración local.

Comenzó el conferenciante destacando las virtualidades de la investigación histórica para conocer el sentido actual de las instituciones y su proyección futura, idea que tiene especial aplicabilidad con respecto a la Administración local.

De acuerdo con esa idea, expuso cómo el Régimen local recibió la sistematización racionalizadora a finales del siglo XvIII, aunque el intento quedó frustrado ya en sus inicios, al surgir un número excesivo de Municipios. En Francia, el primer proyecto de división municipal, de 1789, congruente con las ideas fisiocráticas, preveía únicamente 700 Municipios, es decir, grandes Entidades, con una población y una dimensión mínimas...; sin embargo, en la Asamblea triunfó la idea de hacer un Municipio en cada pueblo, por el argumento de que, en caso contrario, se primaría a las villas sobre el campo, y con el resultado de 44.000 Municipios. El principio se importó a España, que lo recibe ya en la Constitución de Cádiz, y aun. que un Decreto de 1813 recomendaba un mínimo de 1.000 habitantes para constituir un Municipio, lo cierto es que el concepto de "pueblo» fue interpretado generosamente, bastando con 100 vecinos para fundar un Municipio.

Los criterios de racionalidad triunfaron, sin embargo, en un nivel superior, el de los Departamentos franceses y las Provincias españolas. El Departamento, en un principio, era un órgano estatal, aunque con cierta representación política - lo que no era nada excepcional en los principios de la Revolución-; sólo a partir de 1810 se le reconoce un patrimonio propio, personalidad jurídica... Pautas éstas que también siguió la Provincia, en un evidente mimetismo con Francia, aunque la artificialidad de la división es más 
matizada. En efecto, Javier DE BuRgos dividió en Provincias los antiguos Reinos siguiendo, en lo posible, los criterios tradicionales.

En toda esa corriente histórica, afirmó el conferenciante, hay tres frustraciones. Por abajo, la Parroquia (Galicia) y la Comarca (Cataluña); por arriba, la Región. Esos tres elementos nutren las reivindicaciones nacionalistas.

Pues bien, a partir de esta interpretación de unos datos históricos, el conferenciante dijo que la Constitución destruye el Estado centralista, llevada de una fe absoluta en el principio de autonomía; lo que, en su opinión, quizá no haya sido positivo.

La Constitución diseña un tipo de Estado que va más allá del sistema regional o federal. Lo que se ha pretendido, dijo el conferenciante, es destruir el Estado liberal, con un reverdecimiento de los planteamientos carlistas.

El sistema resultante es contrario a la racionalidad. Se agrede a la Provincia con la transferencia de la Administración periférica del Estado a las Comunidades Autónomas, con la superposición del Delegado del Gobierno... La Provincia está acorralada, incluso se ha suprimido en las Comunidades Autónomas uniprovinciales. Se ha perdido toda uniformidad en las divisiones territoriales, arbitrando Comunidades grandes, pequeñas y con organizaciones diferentes. Lo mismo sucede en relación con los Municipios, resultando imprecisa la atribución de competencias sobre el diseño de la estructura municipal.

Concluyó su intervención criticando la falta de racionalidad de las soluciones organizativas en marcha, por la incidencia de criterios historicistas, y auspiciando un retorno a los planteamientos racionalizadores.

8) La segunda conferencia de la tarde fue pronunciada por el profesor Sebastián MARTín-RETORTILLo, Catedrático de Derecho Administrativo en la Universidad Complutense de Madrid, con el título Presente y futuro de las Diputaciones Provinciales.

Inició su disertación refiriendo la idea de que en los procesos históricos de afianzamiento de las instituciones son frecuentes los intentos de abatirlas. A pesar de ello, hay instituciones que sobreviven, que permanecen. La licitud de su existencia debe medirse por el criterio de si sirven o no para cumplir con objetividad algunos intereses generales.

No cabe duda que las Diputaciones Provinciales constituyen un tema-testigo de esas cuestiones. En un lento camino, pese a todas 
las dificultades, se han ido afirmando; de cada uno de los grandes ataques contra la Provincia (1868, 1931, 1978), ésta siempre ha salido fortalecida («la venganza de la Provincia», decía Nicolás PÉrEZ SERRANO), como ha demostrado el propio conferenciante en otro estudio.

Pero marginando las vicisitudes históricas de la Provincia, el conferenciante planteó su disertación a partir de la Constitución de 1978, con la idea de responder a la pregunta de si sirven o no sirven, en la actualidad, las Diputaciones Provinciales para hacer efectivo el modelo territorial de distribución del Poder.

En la Constitución, la Provincia recibe un tratamiento escueto, por comparación con las Comunidades Autónomas, aunque de ahí no deba deducirse una falta de precisión del texto fundamental. Los artículos 137 y 141 reconocen y generalizan la fórmula de las Diputaciones Provinciales. Existe una garantía institucional de las Provincias, conforme a un planteamiento seguido en los Estatutos de Autonomía y afirmado por el Tribunal Constitucional en sus sentencias de 28 de junio de 1981, sobre la Ley catalana de Diputaciones Provinciales; de 16 de mayo de 1983, sobre la Ley Orgánica de Elecciones locales; de 5 de agosto de 1983, sobre la LOAPA. De ese planteamiento únicamente discrepa el profesor SANTAMARía, en cuyos argumentos penetró el conferenciante para rechazarlos, concluyendo que la garantía institucional quiebra si se menoscaban el contenido y las funciones de las Diputaciones.

Las Provincias han reafirmado su presencia a través de los Estatutos de Autonomía, destacadamente a partir de la aprobación del Estatuto Gallego. Se las ha implicado en el proceso autonómico con fórmulas potenciadoras. En tal sentido, afirmó que las funciones de coordinación de las Diputaciones Provinciales por la Comunidad Autónoma no debían interpretarse como una sustracción de competencias. Se refirió también a la técnica de utilización de las Diputaciones por las Comunidades para el cumplimiento de sus servicios periféricos, primando así el criterio de eficacia y ahorro que propugnó el Informe de la Comisión de Expertos sobre la autonomía y que ha respetado la reciente sentencia del Tribunal Constitucional sobre la LOAPA.

Explicó también el conferenciante los cambios políticos del partido en el Gobierno a propósito de la Provincia. Hasta la época de aprobación de la Constitución, el PSOE era marcadamente provincialista. Si modificó algunos aspectos de esa postura fue a raíz del 
resultado de las elecciones locales de 1979. Pero justamente el Informe de la Comisión de Expertos marcó el punto de inflexión y la vuelta del partido al planteamiento provincialista. No debe extrañar así que el anteproyecto de Ley de Bases de Régimen local fortalezca a la Provincia.

La cuestión de si sirven o no hoy las Diputaciones Provinciales, debe plantearse, como toda opción organizativa, desde la óptica del artículo 9, 2. ${ }^{\circ}$, de la Constitución y del cumplimiento de los fines de un Estado social. Pues bien, el conferenciante estimó que las Diputaciones podían desempeñar un importante papel en la tarea de corregir los desequilibrios intrarregionales, no menos profundos que los interregionales. Las Diputaciones pueden servir de contrapeso a las metrópolis, constituyéndose en cauce de ordenación territorial. Las Diputaciones serían también una vía adecuada para abordar el tema de los pequeños Municipios y de los Municipios rurales, a través de una labor de fomento, asistencia, promoción; partiendo de la idea de que esa labor no sólo respeta la autonomía municipal, sino que justamente la posibilita. Por último, destacó las posibilidades de las Diputaciones como engranajes del proceso autonómico.

Estas nuevas perspectivas deben conducir, sin embargo, a una profunda reconsideración de los mecanismos y modos de actuación de las Diputaciones Provinciales. Habló el conferenciante de la necesidad de una auténtica reconversión de estos Entes para asumir las mayores y nuevas obligaciones.

Las Diputaciones pueden constituir incluso un esquema adecuado para la comarcalización, aunque aseguró que no podía pensarse en generalizar la Comarca, entre otras razones, por dificultades derivadas de la variedad de necesidades de los distintos servicios públicos.

Terminó la conferencia aludiendo a los intentos de algunas Comunidades Autónomas de desmontar las Diputaciones Provinciales esgrimiendo el título de su función coordinadora; intento de desmontar unas organizaciones acreditadas que es de esperar no prospere.

9) Día 28. Inició la sesión el profesor Luciano PAREJo ALFOnSo, Catedrático de Derecho Administrativo en la Universidad de La Laguna, en situación de excedencia especial por su nombramiento como Director del Instituto de Estudios de Administración Local, quien expuso la conferencia titulada El Régimen local y la delimitación de la autonomía de Municipios y Provincias.

Empezó refiriéndose a la problematicidad siempre inherente a la 
posición del poder local en la estructura del Estado, destacando que la consideración del Municipio como un Ente natural -asumida por el Estatuto de Calvo Sotelo o el Texto Refundido de la Ley de Régimen local de 1955- llevaba a situar al Municipio fuera de la organización territorial del Estado; sistema dualista que no puede tener cabida en el diseño de la Constitución de 1978, donde Provincias y Municipios se conciben, según ha precisado el Tribunal Constitucional en su sentencia de 2 de febrero de 1981, como partes de una totalidad.

Aplicó el conferenciante a los Entes locales la calificación de Entes de relevancia constitucional, de acuerdo con la terminología italiana, afirmando que de ahí no podía derivarse una configuración política. El tránsito de la función administrativa a la vertiente política en las Administraciones locales pondría en peligro la integridad nacional. En este sentido, puso de relieve la consolidación histórica del carácter no político, sino simplemente administrativo, de los Entes locales.

Tras destacar la importancia del escalón local para alcanzar los objetivos del Estado social de Derecho, pasó a analizar el contenido de la expresión Régimen local y la distribución de competencias sobre el mismo entre el Estado y las Comunidades Autónomas. En Alemania, la postura clásica consideraba el Régimen local como una materia atribuida a los Estados miembros que incluía unitariamente las cuestiones organizativas y competenciales; modernamente, se ha formulado la tesis que identifica el Régimen local $\mathrm{y}$, por tanto, las competencias de los Estados miembros, con los aspectos organizativos, excluyendo la atribución de concretas competencias, que dependería del legislador sectorialmente competente. Aplicando esa nueva teorización al esquema de distribución de competencias trazado por la Constitución. Española de 1978, entendió que el artículo $149,1^{\circ}, 18 .^{\circ}$, atribuye al Estado la legislación básica del Régimen local, sin incluir las concretas materias de competencia local.

El anteproyecto de Ley Básica de Régimen local asume esta perspectiva, regulando, en consecuencia, solamente lo relativo a organización, funcionamiento y régimen jurídico de las Corporaciones locales. El sistema de fuentes se complica por la incidencia, a partir de esa Ley Básica, de la legislación autonómica de desarrollo y las ordenanzas municipales.

En cuanto a las competencias locales, el anteproyecto de Ley Básica de Régimen local se limita a enunciar la regla general de la 
necesaria presencia de las Corporaciones locales en la gestión de una serie de materias que se enumeran. Con ese principio queda salvada la garantía institucional de tales Corporaciones, dejando la atribución de las concretas competencias en tales materias a las leyes sectoriales - del Estado o de las Comunidades Autónomas, según a quien pertenezca la potestad legislativa sobre la materia en cuestión-.

10) Clausuró la «Semana» el profesor Antonio EmBID IRUjo, Titular de Derecho Administrativo en la Universidad de Zaragoza y también en excedencia especial por su nombramiento como Presidente de las Cortes de Aragón, quien habló de Las relaciones entre las Diputaciones Provinciales y las Comunidades Autónomas.

Destacó la ubicación del tema de su conferencia entre las exigencias de concreción técnica del Estado de las Autonomías. Dio también algunas referencias históricas sobre las relaciones entre Diputaciones Provinciales y Entes regionales. Así, por ejemplo, el Estatuto Catalán de 1932 preveía la competencia exclusiva de la Generalidad sobre el Régimen local, lo que llevó a la supresión de las Provincias, conforme a un planteamiento que reverdece tras el Estatuto de 1979. En Aragón también hubo recelos provincialistas durante la Segunda República.

En la experiencia más reciente, la instauración de regímenes preautonómicos preveía relaciones con las Diputaciones, pero sin que se obtuvieran resultados prácticos. En los Estatutos de Autonomía, la falta de un modelo de estructuración territorial llevó a mantener el statu quo.

A continuación, describió las diversas fórmulas de relación entre las Diputaciones Provinciales y las Comunidades Autónomas. La primera posibilidad consistiría en la asunción de las competencias provinciales por las Comunidades, según el modelo de la Ley Catalana de Diputaciones. Aunque el conferenciante no dejó de reflejar la existencia de opiniones discrepantes de la sentencia del Tribunal Constitucional que declaró la inconstitucionalidad de los preceptos fundamentales de tal Ley, en su opinión, es adecuado el sentido de la doctrina sustentada por el Tribunal, lo que debe conducir a descartar esta fórmula.

Una segunda técnica de relación consiste en la coordinación de las competencias de las Diputaciones Provinciales por la Comunidad Autónoma, según el modelo de las Leyes Andaluza y Valenciana de Diputaciones. La coordinación no supone relación de jerarquía; sin 
embargo, la Ley Valenciana utiliza técnicas propias del principio jerárquico, como las directrices, la suspensión de actos, la unión de presupuestos provinciales y la aprobación de los mismos por la Comunidad Autónoma. El conferenciante propuso, como fórmula para solucionar los problemas derivados de la autonomía presupuestaria de las Diputaciones, el arbitrio de una forma de impugnación privilegiada por la Comunidad de los presupuestos provinciales, con efectos suspensivos, cuando la Diputación incumpla convenios de cooperación, la planificación económica regional o normas con rango adecuado que impongan una actividad a las Diputaciones Provinciales.

La tercera fórmula, propiciada por la Ley del Proceso Autonómico, consiste en la transferencia o delegación de competencias de las Comunidades Autónomas en las Diputaciones Provinciales. Tras analizar las dificultades y problemas que presenta, se refirió a una cuarta técnica, la gestión por las Diputaciones Provinciales de los servicios periféricos de las Comunidades Autónomas.

Concluyó insistiendo en que cualquier construcción que intente desconocer la Constitución y la interpretación de la misma fijada por el Tribunal Constitucional, es una construcción fantástica en la que no merece la pena adentrarse. Idea que aplicada a la Provincia significa que ésta no puede ser debilitada por la Comunidad Autónoma.

11) La crónica de las distintas conferencias debe entenderse, claro está, sujeta a los posibles, y difícilmente evitables, errores que la transmisión oral de unas ideas conlleva. No obstante, de su contenido esencial, cabe deducir la falta de un consenso generalizado, a nivel doctrinal, en relación con aspectos relevantes de la Administración local.

Obsérvese que las discrepancias alcanzan a la misma sustancia y valor del principio autonómico, si bien la consideración negativa del mismo fue, en verdad, abiertamente minoritaria (PARADA) entre los conferenciantes. Es decir, la opinión más extendida parece concebir las cuestiones del Régimen local como un tema clave en la distribución territorial del Poder, profundamente relacionado con la realización de los objetivos del Estado social de Derecho (así, expresamente, Martín Rebollo, S. Martín-Retortillo y Parejo).

Sin embargo, como decía, no todos los problemas parecen recibir soluciones mayoritariamente aceptadas. La recepción de la moderna doctrina alemana sobre el Régimen local, con sus importantes con- 
secuencias de cara a la distribución de competencias entre el Estado y las Comunidades Autónomas y también sobre la misma posición de los Entes locales, concebidos no como Entes separados, sino como partes de un todo; la recepción de esa doctrina, expresamente aludida por algunos de los intervinientes (MARTín REBOLLO, MUÑoz MACHADO, PAREJo), no deja de presentar problemas de concreta articulación que requerirán una profundización, dado el peso de una tradición histórica centralista no desconocida por los conferenciantes. Porque los pequeños matices observables en las enunciaciones principales tienen hondas consecuencias en el régimen jurídico de las instituciones. Y también porque las características propias de la configuración histórica de los Entes locales en España no siempre harán posible trasposiciones de doctrinas surgidas en otro contexto, como parece sugerir la reflexión sobre alguna experiencia territorial (SANTAMARfa).

Nos encontramos así con un tratamiento que presenta diferencias no silenciables en puntos de tan gran trascendencia como la posición de las Diputaciones Provinciales. Hubo conferenciantes que, con argumentos de fondo, se mostraron partidarios de su fortalecimiento (S. MARTíN-RETORTILLO), mientras que otros se situaron en una perspectiva distinta, tratando que la regulación de las Provincias no condujera a menoscabar su garantía institucional (MUÑoz MACHADO, EMBID). Aunque las posiciones no sean opuestas, sería ingenuo desconocer las diferentes consecuencias que pueden acarrear en la concreta instrumentación del nivel provincial.

Otro ejemplo. La cuestión relativa al tipo de controles que deben arbitrarse sobre la concreta actividad de los Entes locales. Hubo conferenciantes que, congruentes con el encaje de la Administración local en un esquema organizativo general, se mostraron partidarios de la existencia, al menos en algunos supuestos, de controles de oportunidad en vía administrativa (MARTín Rebollo, MuÑoz MACHADO). Mientras que para otros oradores debía de mantenerse el sistema de controles judiciales de legalidad por el que opta la Ley 40/1981 (SoSA); posición de gran trascendencia frente a tradicionales regímenes históricos (SANTAMARía).

Añadiré también que, en general, los conferenciantes situaron sus intervenciones en el marco de las "grandes» cuestiones que presenta el Régimen local, sin penetrar en las cuestiones "menudas», de detalle (aunque hubo excepciones: Santamaría, L. Martín-ReTORTILlo). Observación que realizo no con ánimo de crítica; es más, 
la opción parece razonable tratándose de intervenciones orales y habida cuenta de la finalidad del ciclo. La observación serviría, pues, en mi criterio, para poner de relieve la necesidad de más estudios, de mayor divulgación y debate sobre todos los aspectos de las Administraciones locales.

En este sentido, podrían destacarse algunos elementos problemáticos con respecto a la forma en que, al parecer, pretende regularse la materia. El anteproyecto de Ley Básica del Régimen local se centra sólo en ciertos aspectos de los tradicionalmente incluidos en la legislación de Régimen local (SoSA). Se opta así por la importación de los avances del régimen federal alemán, a que antes me referí, al propio tiempo que se trata de limitar el contenido normativo elaborado por el Estado a los elementos básicos. Pues bien, esa opción creo que abre el debate - un debate que, desgraciadamente, no pudo desarrollarse en el ciclo de conferencias- en lo referido a la exclusión de materias determinadas y en el punto de si es adecuado, de cara a los concretos elementos regulados, exigir a todas las Comunidades Autónomas la aprobación de leyes complementarias. Es decir, se plantea la cuestión de si la ley estatal debe ser únicamente ley básica o debe cubrir también el círculo de suplencia, no obligando de esta manera a todas las Comunidades a aprobar la legislación de desarrollo.

En definitiva, el brillante conjunto de conferencias expuestas en la «Semana sobre la Constitución y la Administración Local» quizá debiera deparar la aparentemente paradójica consecuencia de que resulta necesario proceder con más calma en la formulación de una ley estatal de Régimen local. El anteproyecto de Ley Básica, con sus exclusiones y su necesario complemento por la legislación autonómica, pudiera suscitar dudas razonables - que, sin embargo, no pudieron debatirse en las sesiones de la «Semana», al no estar previsto un tiempo para el coloquio- sobre si facilitará o no el normal desenvolvimiento de la Vida local, el desarrollo de una Vida local que quizá necesite textos normativos claros, completos (comprendiendo las bases y el derecho supletorio en la ley estatal), con el menor número de lagunas posible. Estoy seguro que merecería la pena abrir un amplio debate - de corte político y de corte técnicosobre esa cuestión, al objeto, cuanto menos, de dar una cumplida explicación a la necesidad, que parece exigir el anteproyecto, de transferir (por la vía del artículo $150,2 .^{\circ}$, de la Constitución) a la mayoría de las Comunidades Autónomas las potestades legislativas 
118 REVISTA DE ESTUDIOS DE LA VIDA LOCAL

de desarrollo del Régimen local, de las que en la actualidad carecen. Es decir, en la distribución de competencias que resulta de la Constitución y de los Estatutos de Autonomía, el Régimen local es una materia de entera competencia estatal, salvo para algunas Comunidades Autónomas que asuman competencias sobre la materia dentro del respeto a las bases estatales, y salvo en los concretos aspectos que pueden ser asumidos por las restantes Comunidades, ex artículo $148,1 .^{\circ}, 2 .^{a}$, de la Constitución. ¿Es razonable modificar ese esquema, modificarlo de manera sustancial en la primera ocasión que se plantee? 
REVL-1984, núm. 221. LOPEZ RAMON, FERNANDO. CRONICA DE LA SEMANA DE ESTUDIOS SOB...

REVISTA

DE

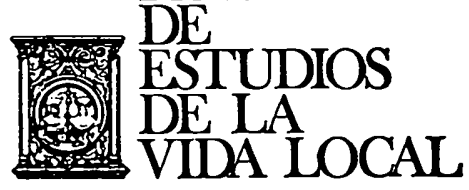

III. ESTADISTICA

REVL-1984, núm. 221. LOPEZ RAMON, FERNANDO. CRONICA DE LA SEMANA DE ESTUDIOS SOB... 
REVL-1984, núm. 221. LOPEZ RAMON, FERNANDO. CRONICA DE LA SEMANA DE ESTUDIOS SOB...

REVL-1984, núm. 221. LOPEZ RAMON, FERNANDO. CRONICA DE LA SEMANA DE ESTUDIOS SOB... 